\title{
EL FACTOR RELIGIOSO EN LA ACTIVIDAD POLÍTICA Y SOCIAL DE LOS LINAJES DE LA ALTA NOBLEZA EN LA REGIÓN SORIANA A FINES DE LA EDAD MEDIA
}

\author{
POR \\ Máximo Diago Hernando \\ Centro de Ciencias Humanas y Sociales, CSIC, Madrid
}

\section{RESUMEN}

El autor analiza algunos aspectos de la religiosidad y de la política puesta en práctica por los miembros de la alta nobleza en sus relaciones con las instituciones eclesiásticas, en el ámbito de la Corona de Castilla a fines de la Edad Media. Para profundizar en el análisis de esta temática delimita un espacio geográfico concreto, el de la región en torno a la ciudad de Soria, y presta atención a los tres grandes linajes que mayor influencia política ejercieron en el mismo, el de los Arellano, condes de Aguilar; el de los Mendoza, condes de Monteagudo, y el de los De La Cerda, condes y luego duques de Medinaceli.

PAlABRAS ClAVE: Baja edad media, Corona de Castilla. alta nobleza, Religiosidad, instituciones eclesiásticas

\section{THE RELIGIOUS FACTOR IN THE POLITICAL AND SOCIAL ACTIVITIES OF THE HIGH NOBILITY LINEAGES IN THE REGION OF SORIA AT THE END OF THE MIDDLE AGES}

\begin{abstract}
The author analyses some aspects of the religiosity and of the policy adopted by the members of the High Nobility in their relationship with the ecclesiastical institutions in the Crown of Castile at the end of the Middle Ages. In order to be able to analyse this subject in greater depth, he chooses the Castilian region that had its capital in the town of Soria. He pays attention to the three noble lineages that exercised greater political influence in this region: the Arellano, counts of
\end{abstract}


Aguilar, the Mendoza, counts of Monteagudo, and the La Cerda, counts and later dukes of Medinaceli.

KEY WORDS: late middle ages. Crown of Castile. high nobility. religiosity. ecclesiastical institutions.

Recibido/Received 20-11-2009

Aceptado/Accepted 14-09-2011

En las sociedades europeas bajomedievales se dio una notable convergencia entre política y religión, en claro contraste con lo que en las del mundo occidental actual se considera como meta perseguible y deseable, que es la plena separación de ambas esferas. Las creencias religiosas no se consideraron en el mundo medieval como elementos que debían quedar relegados a la esfera privada del individuo, sin interferir en su vida pública. Por el contrario no se concebía que la vida en sociedad pudiese estar regida por otros principios distintos de los preconizados por dichas creencias, que se daba por supuesto que debían ser compartidas por todos.

En este contexto, al centrar nuestra atención en un ámbito concreto de la Europa Occidental como es la Corona de Castilla durante el período medieval, podemos explicarnos el lugar central que entre las prioridades de los miembros de la alta nobleza, el grupo más influyente entonces de la sociedad política junto a la Monarquía, ocuparon los asuntos de índole religiosa en sus más diversas manifestaciones. Del mismo modo, también encuentra una más fácil explicación el hecho de que los nobles se esforzasen por participar en la regulación de aspectos de la práctica religiosa que, desde la perspectiva de nuestras actuales sociedades secularizadas, nos parecen de exclusiva incumbencia del clero.

Los nobles castellanos de fines del Medievo adoptaron, no obstante, posturas contradictorias en sus actuaciones en este terreno. Así, por un lado, asumieron que las creencias religiosas, tal como eran definidas por las autoridades eclesiásticas, habían de ser los principios rectores por antonomasia de la vida en sociedad, y debían inspirar sus actuaciones no sólo como personas particulares sino también como gobernantes. Pero, por otro lado, con extraordinaria frecuencia, mostraron comportamientos que contradecían flagrantemente dichas creencias, tanto en el espíritu como en la letra.

Esta falta de correspondencia entre adhesión a unos determinados postulados religiosos y el régimen de vida adoptado en la práctica la podemos percibir en muchos terrenos. Así cabe destacar, por ejemplo, su frecuente recurso a la violencia, que no respetó en muchos casos ni siquiera los recintos sacros. Y, por otro lado, también su vida sexual, caracterizada por la frecuencia de las relaciones adúlteras públicas, que dieron lugar al nacimiento de un gran número de bastardos. 
Por supuesto, se ha de precisar que lo mismo ocurría entre los reyes y demás miembros de las familias reales, y entre muchos miembros del propio estamento clerical. Estos últimos, en efecto, en bastantes casos adoptaron formas de vida que apenas difirieron de las de los representantes más turbulentos de la nobleza laica, con el agravante de que los clérigos de órdenes mayores habían hecho voto de castidad y no debían bajo ningún concepto derramar sangre, ni siquiera cuando habían de ser ejecutadas sentencias judiciales.

No nos detendremos aquí, sin embargo, a reflexionar sobre el significado de este fenómeno, constatado una y otra vez a lo largo de la historia en sus más diversas manifestaciones. Por el contrario, más que el hecho de que los nobles castellanos de la Baja Edad Media con frecuencia tuviesen comportamientos incompatibles con los principios religiosos por ellos asumidos y defendidos, lo que consideramos más característico de este período, en relación con otros momentos de la historia, es la propia centralidad que las cuestiones estrictamente religiosas tuvieron en la vida pública y privada de dichos nobles, y en su faceta como gobernantes de sus lugares de señorío. Por esta razón nos centraremos en el presente trabajo en dar cuenta de esta peculiaridad de la sociedad castellana bajo medieval, llamando la atención sobre las múltiples formas en que las creencias religiosas de los miembros de la alta nobleza influyeron y tuvieron una traducción tanto en su vida social como en su acción de gobierno. Para ello hemos optado por circunscribir nuestro análisis a una región en concreto de la Corona de Castilla, la fronteriza con los reinos de Aragón y Navarra que tenía su centro en la ciudad de Soria, prestando atención a los tres linajes de alta nobleza que dominaron a fines de la Edad Media su vida política, a saber, los Arellano, señores de Cameros y condes de Aguilar, los Mendoza, señores de Almazán, y los de La Cerda, condes y luego duques de Medinaceli.

\section{EL DESTINO DE MIEMBROS DE LAS FAMILIAS DE LA ALTA NOBLEZA} A LA VIDA EN RELIGIÓN

Las familias de la nobleza, siendo consecuentes con el papel central que asignaron a las creencias religiosas en sus actuaciones públicas y privadas durante el período bajomedieval, destinaron a un número relativamente importante de sus miembros al estamento eclesiástico, que en la época alcanzaba unas dimensiones mucho mayores que en la actualidad, y que además disfrutaba de una serie de privilegios jurídicos, con evidentes traducciones en el terreno político, que fueron radicalmente suprimidos en el siglo XIX con la implantación de los regímenes liberales. Pero estas familias, a la hora de decidir cuáles de entre sus miembros habían de dedicar sus vidas a servir a la Iglesia, lo hicieron siguiendo unas pautas que demuestran que actuaron no sólo movidos por 
motivaciones de tipo estrictamente religioso, sino que tanto o mayor peso tuvieron a la hora de tomar sus decisiones otras de cariz más decididamente político o social, cuando no económico.

Así, desde el punto de vista de la incorporación de miembros de las familias nobles al estamento eclesiástico, cabe advertir un evidente contraste entre varones, en especial si habían nacido de legítimo matrimonio, y hembras. Las familias de la alta nobleza que estamos aquí tomando en consideración, como en general todas las de la Corona de Castilla en el período bajomedieval y altomoderno, destinaron de forma sistemática a alguna de sus hijas, cuando las hubo, a la vida conventual, para que profesasen en monasterios benedictinos o cistercienses, o en conventos de las Órdenes Mendicantes.

Las comunidades monásticas elegidas fueron en bastantes casos las más próximas a sus respectivos estados señoriales. Pero no ocurrió así siempre, pues se conocen algunos casos de profesión en comunidades monásticas de elevado prestigio alejadas de los territorios donde el linaje ejercía su dominio, como, por ejemplo, el monasterio de Las Huelgas de Burgos, ${ }^{1}$ o el de Santa Clara de Tordesillas. ${ }^{2}$

Con frecuencia estas mujeres asumieron en breve plazo posiciones dirigentes en las comunidades en que ingresaron, pues consta que varias llegaron a ser elegidas abadesas. Así, Constanza de Arellano, hija del señor de Cameros, y hermana del primer conde de Aguilar fue, como hemos avanzado, abadesa de Santa Clara de Tordesillas. Y, por su parte, el monasterio cisterciense de Santa María de Herce estuvo ininterrumpidamente gobernado por mujeres pertenecientes a este mismo linaje durante toda la segunda mitad del siglo XV y la primera mitad del siglo XVI. En concreto, Leonor de Arellano, hermana también del primer conde de Aguilar, que había ingresado en él aportando como dote un juro de heredad de 11.500 mrs. de renta anual que le cedió su padre, el señor de Cameros, fue su abadesa desde 1474 hasta el año de su muerte, 1501. Y a partir

\footnotetext{
${ }^{1}$ En concreto dos hermanas del primer conde de Aguilar, doña Leonor y doña Elvira de Arellano, profesaron en el monasterio cisterciense de Las Huelgas de Burgos. AHN (=Archivo Histórico Nacional), Títulos y Familias, Señorío de Cameros, carpeta 11, $\mathrm{n}^{\circ}$. 124. Confirmación de la renuncia de la abadesa de Las Huelgas de Burgos, en el año octavo del pontificado de León X, a la herencia que pudiese corresponder a doña Leonor y doña Elvira de Arellano, por las que había entregado al monasterio su hermano, el conde de Aguilar, Alonso de Arellano, 200.000 mrs. de dote.

${ }^{2}$ En el monasterio de Santa Clara de Tordesillas profesaron varias mujeres del linaje de los Mendoza. Por ejemplo Beatriz de Mendoza, hija de Diego de Mendoza, señor de Villasayas, llegó a ser abadesa de este monasterio, y su hermana Juana profesó en él como monja. Allí también profesó Ana de Mendoza, hija de Pedro de Mendoza y María de Zúñiga, señores de Hinojosa de la Sierra. También en este monasterio lo hizo Constanza de Arellano, hija de Juan Ramírez de Arellano, señor de Cameros, y de Isabel Enríquez, que llegó a ser abadesa del mismo. Noticia en RAH, Salazar y Castro, C-34, fols. 106 y ss.
}

Hispania Sacra, LXIII

127, enero-junio 2011, 7-39, ISSN: 0018-215-X 
de esta fecha le sucedió en el puesto su sobrina Juana de Arellano, hija de Carlos de Arellano, señor de Ausejo, Murillo y Alcanadre.Se da la circunstancia además de que ésta, en el momento de la muerte de su tía, era todavía seglar, y en el plazo de una semana tomó el hábito y el velo, para poder ser designada abadesa. $^{3}$

Mujeres del linaje Mendoza también llegaron a ocupar puestos dirigentes en el monasterio de Santa Clara de la villa de Almazán. En concreto, Constanza de Zúñiga, en ocasiones identificada en los documentos como Constanza de Mendoza, fue abadesa de este monasterio cuando su hermano, el conde de Monteagudo, Don Antonio de Mendoza, ejercía el señorío jurisdiccional sobre la villa de Almazán. Por razones que no hemos llegado a precisar, más adelante abandonó, sin embargo, esta casa, para terminar profesando en un monasterio perteneciente a otra orden, la de Sancti Spiritus, el monasterio de la Fuensanta, ubicado en la villa vallisoletana de Portillo, donde residía en 1543. Ese año precisamente pleiteó con su hermano el conde, a quien reclamó el pago de las cantidades de dinero que le debía, por razón de una pensión de 2.500 mrs. anuales que estaba obligado a entregarles a ella y a su hermana, Francisca de Mendoza, también monja en Santa Clara de Almazán. ${ }^{4}$

La frecuencia con que las mujeres de los linajes de la alta nobleza hicieron profesión de votos monásticos, sobre todo en comunidades cistercienses o de clarisas, contrasta con la poca predisposición de los varones de esos mismos linajes a incorporarse al clero regular. Son pocos los individuos procedentes de los linajes de la alta nobleza a los que encontramos identificados en las fuentes documentales como monjes o frailes.

Además, estas mismas fuentes contienen noticias que proporcionan indicios claros de que en estos linajes no sólo no se alentó la entrada en monasterios y conventos de sus varones, como se hizo en el caso de las hembras, sino que incluso en ocasiones se trató de impedirla, recurriendo a la violencia, cuando alguien trató de hacerlo por su propia iniciativa.

Así nos lo confirma, por ejemplo, la noticia de que en 1515 el monasterio benedictino de Santa María de Valvanera se vio obligado a solicitar carta de seguro a los Reyes Católicos porque temía ser atacado por la condesa de Aguilar, debido a que había sido recibido como monje en él su hijo Antonio de Arellano. 5 No era

\footnotetext{
3 Vid. Máximo Diago Hernando, «Un monasterio cisterciense femenino en tierras riojanas. Herce entre los siglos XIII y XVI» Cistercium 188 (1992) 129-52. Y Real Academia de la Historia, Salazar y Castro, D-9, fol. 126.

${ }^{4} \mathrm{AChV}$ (=Archivo de la Chancillería de Valladolid), P.C. (=Pleitos Civiles) Pérez Alonso, F. (=Fenecidos) C. 847-5.

${ }^{5}$ La carta de seguro en AGS (=Archivo General de Simancas), RGS (=Registro General del Sello), V-1515.
} 
un temor infundado, pues había precedentes de ataques perpetrados por miembros de la alta nobleza en monasterios localizados en sus ámbitos regionales de influencia.

En concreto, unos cuantos años antes se había planteado muy cerca de Valvanera, en el monasterio jerónimo de Santa María de la Estrella, un problema muy parecido. En 1498, un hermano de Antonio de Velasco, conde de Nieva, llamado Pedro de Velasco estaba a punto de profesar, cuando acudió al monasterio el conde en persona al frente de un grupo de gente armada para llevárselo por la fuerza. Acto seguido le forzó a tomar de nuevo los hábitos de seglar, si bien poco después los Reyes Católicos ordenaron que se le devolviese al monasterio para que allí manifestase libremente su voluntad sobre si deseaba profesar como religioso. Durante su estancia fuera del monasterio el conde le obligó, no obstante, a que otorgase testamento, en el que renunció a favor del conde la legítima que le correspondía heredar de su padre, Sancho de Velasco. Este testamento fue luego anulado por el propio Pedro de Velasco, tras haber profesado como jerónimo, alegando que había sido engañado al otorgarlo. Y en su nuevo testamento designó como heredero universal de sus bienes al monasterio de la Estrella, en el que había profesado. ${ }^{6}$

Son, pues, muchos los indicios que nos invitan a sospechar que, en este caso, la cerrada oposición del conde de Nieva a que su hermano ingresase en el referido monasterio jerónimo obedeció ante todo a un evidente interés por evitar que la parte del patrimonio familiar que correspondía heredar a este hermano terminase en poder de dicha institución eclesiástica.

En relación a este hecho cabe recordar que las mujeres pertenecientes a linajes de alta nobleza ciertamente aportaron cantidades importantes de bienes cuando hicieron profesión en comunidades monásticas, pero, sin excepción, se trató de bienes por valor muy inferior al de las legítimas que en principio tenían derecho a heredar a la muerte de sus padres. Por supuesto, también era muy inferior al de las dotes que recibieron sus hermanas que contrajeron matrimonio.

Se puso, por tanto, siempre buen cuidado en exigir que los monasterios renunciasen explícitamente a reclamar cualquier derecho a la herencia de las legítimas de estas doncellas que entraban en ellos como monjas, una vez cobrados los bienes que debían aportar como dote.

\footnotetext{
${ }^{6}$ El testamento de fray Pedro de Velasco, en el que recoge con detalle los avatares de su vida, y las resistencias de su hermano el conde a su profesión como fraile jerónimo, en AHN, Clero, leg. 3149. Vid. también AGS, RGS, I-1498, fol. 150. Se recoge la denuncia presentada por el conde de Nieva por haber acudido en persona al monasterio jerónimo de Santa María de la Estrella para sacar a la fuerza a su hermano Don Pedro, que había tomado hábito en dicha Orden. Y AGS, RGS, IV-1498, fol. 185. Carta de seguro al monasterio de la Estrella frente a posibles ataques del conde de Nieva.
} 
En la resistencia ofrecida por los linajes de alta nobleza al ingreso de sus miembros varones en las filas del clero regular, por tanto, con bastante frecuencia hubo un motivo económico, aunque probablemente no fue el único. La forma de vida en los monasterios y conventos, incluso antes de que en ellos se impusiesen las reformas observantes, conllevaba renunciar a una serie de hábitos y costumbres muy arraigadas entre los varones de la nobleza. Incluso quienes optaron, en una decisión puramente personal, por abandonar el siglo, no siempre supieron llevarla hasta sus últimas consecuencias, sino que pronto trataron de dar marcha atrás, y de reincorporarse al estamento laico, después de haber profesado.

Desde este punto de vista resulta ilustrativa la trayectoria de Gastón de la Cerda, hijo del segundo duque de Medinaceli, Juan de la Cerda, habido de su primera esposa, doña Mencía Manuel, al que por orden de nacimiento correspondía heredar el estado señorial del linaje. ${ }^{7}$

En una decisión sin duda sorprendente, a una edad que presumimos temprana, quiso profesar como fraile de la Orden de San Jerónimo, pese a que, a raíz de ello, quedaba inhabilitado para poder suceder a su padre en la posesión y gobierno de su extenso estado señorial. Se trató de un acto, sin embargo, apresurado y poco meditado, habida cuenta que muy pronto se arrepintió y abandonó el monasterio en que había profesado, que debió ser el de San Bartolomé de Lupiana.

$\mathrm{Su}$ deseo de reincorporarse a todos los efectos al siglo tropezó, sin embargo, con la frontal resistencia de sus hermanos menores, nacidos del segundo matrimonio de su padre con María de Silva. Particularmente feroz fue la resistencia de su hermano Juan, llamado a suceder a su padre al frente del estado señorial, quien no vio con buenos ojos que su hermano mayor, después de haber renunciado a la sucesión, dado que sus votos como fraile jerónimo le inhabilitaban para la misma, volviese otra vez a reclamarla. Ambas partes decidieron llevar entonces sus diferencias hasta la Curia romana, para que allí se resolviese si la profesión de Gastón de la Cerda como fraile jerónimo era o no reversible. Una primera sentencia declaró que éste no podía renunciar a su condición de fraile. Gastón, no obstante, apeló de dicha sentencia, por lo que, finalmente, sus hermanos Juan y Fernando, para no seguir demorando la resolución del conflicto, optaron por llegar a un acuerdo amistoso con él, sirviéndose de la mediación del propio emperador Carlos.

Accedieron los tres entonces a poner sus diferencias en manos de dos jueces árbitros, el duque de Béjar y el conde de Cifuentes. Éstos, en mayo de 1539, fijaron por escrito las condiciones del acuerdo para poner fin al litigio. Dispusie-

\footnotetext{
${ }^{7}$ Basamos la reconstrucción de la trayectoria de Gastón de la Cerda en diversos documentos de los que se conserva copia en AChV, P.C. Alonso Rodríguez, D. (=Depositados) 121-1.
} 
ron en concreto que, tras la muerte del duque Juan de la Cerda, le sucediese en el gobierno de sus estados su primogénito Don Gastón con el título de duque de Medinaceli, con derecho a gozar de todas sus rentas, a excepción de las de las villas de Enciso y Deza, reservadas para su hermano menor, Juan de la Cerda. Gastón quedaba obligado a transferir todos los años a este último otras rentas hasta alcanzar la cuantía de 1.400 .000 mrs., incluyendo lo que hubiesen montado las rentas de Enciso y Deza.

Se trataba así de compensar a Juan de la Cerda por ser desplazado de la inmediata sucesión al ducado de Medinaceli, tras la muerte de su padre, que le correspondía en derecho si se admitía que Gastón tenía la condición de clérigo. Se aseguró además a Juan de la Cerda la futura sucesión, para él o para sus descendientes, tras la muerte de Gastón de la Cerda, puesto que éste no podría casarse nunca, dado que sólo se le dejó abierta la posibilidad de tomar el hábito de la Orden de San Juan de Jerusalén, si así lo deseaba.

Esta cláusula relativa a la futura adscripción estamental de Gastón de la Cerda era un tanto confusa, pues no dejaba bien sentado si se le consideraba clérigo o laico, aunque de ella cabe deducir que no se juzgó incompatible la pertenencia a la Orden de San Juan de Jerusalén y ostentar la condición de señor jurisdiccional de un estado de la importancia del ducado de Medinaceli.

A todas luces se trataba de una solución transaccional, con importantes concesiones a las dos partes, para facilitar el acuerdo, pero que, en última instancia, presentaba evidentes contradicciones. Aunque Gastón se comprometió solemnemente a cumplir lo dispuesto en esta concordia pergeñada por el duque de Béjar y el conde de Cifuentes, pronto comenzó a tomar decisiones contrarias a la misma, pues llegó a desposarse con Doña María Sarmiento, hija del conde de Salinas. Esta acción debió agotar la paciencia de su familia y del propio emperador, que redoblaron las presiones ejercidas sobre él, hasta obligarle a hacer una declaración solemne de que no había consumado el matrimonio, ni tenía intención de consumarlo, por estar decidido a hacer profesión en el hábito y Orden de San Juan, en cumplimiento de la concordia.

Ésta fue finalmente presentada al emperador para que la ratificase, añadiendo algunas nuevas cláusulas relativas a la anulación del matrimonio con la hija del conde de Salinas, y a la concesión del título de marqués de Cogolludo a su hermano Juan, tras la muerte de su padre. Carlos V la ratificó por su real provisión, fechada en Barcelona el 10 de noviembre de 1542, y, en cumplimiento de la misma, Gastón de la Cerda, a la muerte de su padre, le sucedió como duque de Medinaceli, pero no pudo legar el ducado a ningún descendiente directo suyo. A su muerte, en efecto, recayó la sucesión al mismo en su hermano menor Juan, resolviéndose de este modo el enrevesado conflicto al que había dado lugar la sorprendente decisión del primero de profesar como fraile jerónimo. 
El caso de Gastón de La Cerda demuestra, pues, que la opción por la carrera eclesiástica no era la considerada idónea ni preferible para los miembros de las casas nobiliarias con perspectivas de suceder en los mayorazgos. Y eran tantos los factores que presionaban sobre éstos para que no la eligiesen que, incluso en los pocos casos en que, movidos por inclinaciones estrictamente personales, optaron por ella no fueron capaces de llevar a sus últimas consecuencias su decisión.

Para otros varones de linajes de alta nobleza, no llamados en principio a suceder en el mayorazgo, la opción de incorporarse al estamento clerical no fue contemplada con tanta prevención, por no decir hostilidad. En todo momento, no obstante, se manifestó una decidida preferencia por que lo hiciesen entrando a formar parte de los cabildos de las catedrales, con vistas incluso a llegar a ocupar alguna silla episcopal, antes que profesando en monasterios o conventos.

La presencia de individuos de familias de la alta nobleza en los cabildos de las catedrales estuvo muy extendida en la Europa Occidental durante el período bajomedieval y altomoderno. Y en algunos territorios incluso se vetó el acceso a los mismos a quienes no formasen parte del estamento noble, como tuvo ocasión de comprobarlo a fines del siglo XV y principios del siglo XVI la acaudalada familia de los Fugger, que chocó con la enconada resistencia del cabildo de la catedral de Augsburg a admitir en su seno a algunos de sus miembros, por su origen plebeyo. ${ }^{8}$

En la Corona de Castilla las familias de la nobleza no llegaron a alcanzar este grado de control de los cabildos catedralicios del que disfrutaron sus pares en el Imperio alemán, pero sí estuvieron muy presentes en ellos, según han demostrado varios trabajos monográficos publicados en los últimos años. ${ }^{9}$

Los linajes tomados en consideración aquí también siguieron esta tendencia general de destinar a algunos de sus miembros segundones a la Iglesia, para que hiciesen carrera como clérigos seculares, aunque con desigual fortuna en el empeño.

En algunos casos la carrera eclesiástica de segundones de los linajes se vio truncada por su falta de inclinación hacia la vida religiosa y los estudios universitarios. Se ve en el análisis de la trayectoria de uno de los hijos del cuarto señor de Almazán, Pedro de Mendoza, el Fuerte, llamado Diego de Mendoza. Su padre lo envió en su temprana adolescencia a Valladolid para que estudiase en su universidad, con el objeto de que más adelante pudiese hacer carrera en la Iglesia, con una titulación.

\footnotetext{
${ }^{8}$ Analiza los conflictos planteados con este motivo entre los Fugger y el cabildo de Augsburg, que se prolongaron durante varias décadas, y terminaron en la Corte Romana, Rudolf KIESSLING, Bürgerliche Gesellschaft und Kirche in Augsburg im Spätmittelalter, Augsburg, 1971.

${ }^{9}$ Una visión de conjunto en torno a esta cuestión en Jorge DíAZ IBÁÑEZ, «La incorporación de la nobleza al alto clero en el reino de Castilla durante la Baja Edad Media» Anuario de Estudios Medievales 35-2 (2005) 557-603.
} 
No debió mostrar suficiente aprovechamiento en los estudios, y por ello el señor de Almazán optó por cambiar de estrategia, disponiendo que Diego se fuese a vivir con el obispo de Osma, Pedro de Montoya, en la esperanza de que este prelado lo pudiese promover en el futuro en la carrera eclesiástica por vía de patronazgo. Tampoco el comportamiento del muchacho en la casa del obispo oxomense respondió a las expectativas del padre, dado que muy pronto dio inequívocas muestras de que carecía de vocación para llevar vida de clérigo, y se mostraba mucho más inclinado hacia las aventuras amorosas.

Por ello, finalmente, el obispo y el señor de Almazán convinieron que la mejor manera de asegurar el futuro del muchacho era casándole con una hija bastarda del propio obispo, María de Montoya, que fue a raíz de ello generosamente dotada por su padre. Diego, por su parte, recibió en herencia del suyo el señorío sobre la villa de Villasayas. ${ }^{10}$

La trayectoria de Diego de Mendoza, señor de Villasayas, que más adelante, gracias a un segundo matrimonio se convirtió en señor de Hinojosa de la Sierra, antigua aldea de la ciudad de Soria, proporciona, por tanto, un ejemplo de cómo en las casas de la alta nobleza la carrera eclesiástica fue considerada una buena vía para dar salida a los segundones del linaje, pero siempre orientada hacia la consecución de influyentes posiciones en el seno del clero secular, con la mirada puesta en última instancia en las sillas episcopales.

A estos segundones se tendió a enviarlos a las universidades, para que, gracias a las titulaciones obtenidas en ellas, pudiesen avanzar con más facilidad en el seno de una Iglesia que, si bien no era todavía una institución «meritocrática» propiamente dicha, sí había alcanzado un grado de sofisticación en su régimen de organización que favorecía que los individuos con mejor preparación intelectual contasen con ventajas a la hora de promocionarse.

El señor de Almazán envió por este motivo a su hijo Diego a la universidad de Valladolid, pero la falta de aprovechamiento de éste en los estudios supuso un primer contratiempo para los planes paternos. Eso forzó un cambio de estrategia. Entonces se buscó en las relaciones de patronazgo el sustituto para los méritos adquiridos mediante el estudio, y de ahí la decisión de que Diego entrase al servicio del obispo de Osma. Pero, a la postre, esta estrategia tampoco funcionó, por la propia falta de inclinación de Diego hacia el modo de vida clerical.

En otras ocasiones el linaje Mendoza, en su rama soriana, tuvo más éxito en sus estrategias para colocar a algunos de sus segundones en puestos eclesiásticos influyentes como clérigos seculares. Cabe recordar que un tío del Diego de Mendoza del que acabamos de hablar, hermano de su padre, llamado Alonso de Mendoza, llegó a ser obispo de Coria entre 1444 y 1455. Luis Hurtado de

${ }^{10}$ Tomamos la información de AChV, P.C. Taboada, F. envoltorio 291-1.

Hispania Sacra, LXIII

127, enero-junio 2011, 7-39, ISSN: 0018-215-X 
Mendoza, hermano del conde de Castro, señor de la villa soriana de Gormaz, ${ }^{11}$ fue abad de San Zoilo de Carrión, y ocupó una posición influyente en el seno del cabildo de la catedral del Burgo de Osma, que le valió que a la muerte del obispo Don Pedro de Montoya, dicho cabildo le designase como su sucesor, aunque, como indicaremos más adelante, finalmente terminó siendo desplazado de la silla episcopal por Diego de Santillán, otro clérigo de origen sevillano que había recibido su nombramiento directamente del Papa.

Los intentos del linaje Arellano por colocar a algunos de sus miembros en posiciones influyentes en cabildos catedralicios también resultaron exitosos en varias ocasiones, pero no ocuparon sillas episcopales. Un hermano del primer conde de Aguilar, don Diego de Arellano, estuvo al frente de la catedral de Calahorra como deán durante muchos años, en el tránsito del siglo XV al XVI. Y en 1520 le sustituyó su pariente Carlos de Arellano. ${ }^{12}$ Además de estos dos, al menos otro miembro del mismo linaje, Álvaro de Arellano. nos consta que accedió al cabildo calagurritano. Fue arcediano de Nájera a partir de 1512.13

De todos ellos fue el deán Don Diego de Arellano el que alcanzó mayor relieve en el escenario político riojano, pues participó de forma muy activa en la vida política de la ciudad de Calahorra. Allí se esforzó, de forma continuada, por conseguir que miembros de su clientela ocupasen algunos de los principales oficios de gobierno concejil, despertando de este modo los recelos de sectores de la sociedad política calagurritana, que denunciaron sus constantes intromisiones. ${ }^{14}$

Ofreció apoyo también en esta misma ciudad a otros miembros de su familia, como su hermano Fadrique de Arellano, a quien en el año 1508 facilitó la entrada, al frente de un nutrido grupo de hombres armados, que formaban parte de su clientela, provocando de este modo una airada reacción de los gobernantes laicos de la ciudad, que consideraron la presencia de tan poderoso caballero en sus calles como una grave amenaza para el orden público. ${ }^{15}$

\footnotetext{
${ }^{11}$ Los condes de Castro, señores de Gormaz, pertenecían al mismo tronco familiar que los señores de Almazán, y los señores de Morón de Almazán, todos descendientes de Juan Hurtado de Mendoza, quien recibió en señorío la villa de Almazán por privilegio de Enrique III. Para más detalles sobre la genealogía de este linaje Vid. Diego Gutiérrez Coronel, Historia genealógica de la Casa de Mendo$z a$, Madrid, 1946.

12 Carlos de Arellano presentó bulas de provisión del deanazgo expedidas en Roma en su favor en sesión del cabildo de Calahorra de 24-XI-1520, según consta por el libro de actas.

13 Álvaro de Arellano tomó posesión del arcedianazgo de Nájera el 12-IX-1512, según consta por el libro de actas del cabildo.

14 Vid. Máximo Diago HeRnando, «Clérigos y laicos en la lucha por el poder en la ciudad de Calahorra a fines de la Edad Media: Los conflictos entre los oficiales del concejo y el cabildo de la catedral» Berceo 148 (2005) 93-124.

15 Vid. AGS, Cámara-Personas, leg. 2-233.
} 
Sus relaciones con otros miembros de su familia no siempre fueron de colaboración. Sabemos que con uno de ellos, el señor de Ausejo, Murillo y Alcanadre, Juan de Arellano, mantuvo un prolongado y enconado conflicto por el control de la abadía de la villa de Alcanadre, causa de varios episodios violentos. ${ }^{16}$

Sobre el linaje de La Cerda, no hemos encontrado referencias en la documentación consultada que confirmen que también en él se buscó en la carrera eclesiástica habitualmente salida en esta época para los segundones. No hemos constatado la presencia de alguno de sus miembros en los cabildos catedralicios con sede en las ciudades más próximas al ducado de Medinaceli, como eran los de Sigüenza y Burgo de Osma. Ha de tenerse en cuenta, no obstante, que en los siglos XIV y XV no abundaron los varones en este linaje, y los pocos segundones que hubo pudieron ser convenientemente dotados con pequeños señoríos de vasallos.

\section{FUNDACIÓN DE COMUNIDADES MONÁSTICAS}

Entre las principales manifestaciones de la fuerza que tuvo el sentimiento religioso en los linajes de la alta nobleza en la Corona de Castilla, a lo largo del período medieval, se ha de destacar el importante papel que muchos desempeñaron como fundadores de monasterios. Numerosas fueron en este reino, en efecto, las comunidades monásticas que, desde el período altomedieval y hasta fines de la Edad Media, y aún después, surgieron por iniciativa de representantes de la alta nobleza. Las motivaciones que llevaron a sus miembros a promover el establecimiento de dichas comunidades fueron muy complejas y, en bastantes casos, se ha demostrado que entre ellas tuvieron tanto o más peso que las estrictamente religiosas otras de cariz más propiamente político o social. No deben pasarse por alto, en cualquier caso, las apreciables diferencias existentes en los procedimientos de fundación de monasterios, y en los objetivos perseguidos con ella, en las diferentes etapas del período medieval.

En el período tardomedieval se observa que la mayoría de las fundaciones se realizaron en núcleos urbanos, y que se mostró una decidida preferencia por comunidades pertenecientes a las Órdenes Mendicantes, muy en especial de franciscanos y clarisas. La puesta en funcionamiento de este tipo de comunidades resultaba bastante menos costosa que la de los monasterios benedictinos y cistercienses, erigidos en los siglos del Pleno Medievo, que habían de ser dotados con un importante patrimonio en tierras, para que se pudiesen sustentar los monjes, y otro gran número de laicos que residían en ellos a su servicio. Pese a resultar en principio más fácilmente abordable, se trataba de una empresa que no estaba al alcance de cualquiera. De ahí que no cause sorpresa comprobar

${ }^{16}$ Abundante documentación inédita relativa a este conflicto en AGS, RGS.

Hispania Sacra, LXIII

127, enero-junio 2011, 7-39, ISSN: 0018-215-X 
que fueron sólo los más encumbrados representantes de la alta nobleza, junto con miembros de la realeza, los que acometieron en los siglos bajomedievales fundaciones monásticas.

En la región soriana a fines de la Edad Media, las fundaciones debidas a la iniciativa nobiliaria fueron relativamente escasas, y más bien tardías. Y el mayor protagonismo en esta empresa correspondió al linaje de La Cerda, que contaba con un patrimonio señorial de más envergadura, y, por consiguiente, con mayores fuentes de ingresos.

Al segundo duque de Medinaceli, Juan de la Cerda, se le debe la fundación de dos monasterios, a los que hizo mención expresa en su testamento, uno en sus señoríos sorianos, y otro en los andaluces. ${ }^{17} \mathrm{El}$ primero es el convento de franciscanos que hizo construir extramuros de su villa de Medinaceli, para dotar al cual llegó a expropiar tierras a algunos de sus vasallos, como reconoció en su testamento, en el que dispuso que se compensase a los herederos del difunto receptor Hernando del Águila por una huerta que se les había tomado, para poder dotar de una huerta propia al referido monasterio. ${ }^{18} \mathrm{Y}$ el segundo es el monasterio de la Vitoria, de la Orden de los Mínimos, en la villa de Puerto de Santa María.

Sus esposas también desarrollaron una importante actividad en este terreno. La primera, Doña Mencía Manuel, en su testamento redactado en 1504, hizo alusión a un monasterio que estaba edificando en Puerto de Santa María, en el que dispuso que se celebrasen 10 de los 30 treintenarios que dejó encargados, aunque fue mucho más generosa con el monasterio de San Blas de Villaviciosa, donde se mandó enterrar, al que hizo donación de un total de 300.000 mrs., para la compra de juros y censos, destinados a la dotación de una capellanía perpetua de misa diaria y otras memorias de difuntos que dispuso que se celebrasen en él. ${ }^{19}$

La segunda esposa del duque Juan de La Cerda, Doña María de Silva, asumió la fundación del convento de clarisas de Santa Isabel en Medinaceli, para lo cual donó unas casas en esta villa, e hizo venir de Toledo a una prima suya, Isabel de Toledo, hija del conde de Oropesa, junto con otras tres monjas, que a partir de 1528 fueron el núcleo de la nueva comunidad, siendo la primera abadesa Isabel de Toledo. Se incorporaron acto seguido a la clausura varias damas de compañía de los duques. ${ }^{20}$

17 Para las fundaciones del linaje de La Cerda en Andalucía Vid. José María MiURA-AndRADES, Frailes, monjas y conventos. Las órdenes mendicantes y la sociedad sevillana bajomedieval, Sevilla, 1998, pp. 151-8.

${ }^{18}$ El testamento del segundo duque de Medinaceli, Juan de la Cerda, otorgado en Cogolludo, 18-I1544, en AChV, P.C. Alonso Rodríguez, D, 120-1.

${ }^{19}$ El testamento de Mencía Manuel, otorgado en Medinaceli, 9-VIII-1504, en AChV, P.C. Alonso Rodríguez, D, 120-1.

20 Vid. José Ángel MÁRQuez MuÑoz, «Santa Isabel de Medinaceli. Un convento de clarisas en la villa ducal, desde 1528» Celtiberia 71 (1986) 153-166. 
Se trató, por consiguiente, de un convento en el que las monjas tuvieron fuertes lazos personales con la fundadora que, para reforzarlos aún más, consiguió que poco después, en 1530, el Papa Clemente VII expidiera bula a favor suyo, autorizándola a poder pernoctar en la clausura, acompañada de una dama o doncella. ${ }^{21}$

La actividad como promotor de nuevas comunidades monásticas del padre de Juan de La Cerda, el primer duque de Medinaceli, Luis de la Cerda, fue bastante más modesta, pero, a su iniciativa, se debió la reconstrucción de la iglesia colegial de Santa María, en su villa de Medinaceli. Así lo confesó en su testamento y codicilo del año 1501, haciendo constar que dicha empresa todavía no había llegado a su culminación en aquel momento en que se le acercaba la muerte, por lo que encargó a sus herederos que la acabasen. Ordenó que se le enterrase en la capilla mayor de la iglesia, a la parte del evangelio, en la pared, y que en dicho lugar se construyese una sepultura con «arco y bulto de alabastro, bien labrado y dorado, con los escudos de sus armas».22

Como consecuencia de las labores de reconstrucción llevadas a cabo a iniciativa del primer duque de Medinaceli en la colegiata de su villa ducal, esta iglesia pasó a quedar sometida a una cierta relación de dependencia respecto a la casa ducal, que se tradujo, por ejemplo, en el hecho de que la misma pudo controlar la utilización de sus capillas como lugar de enterramiento, asignándolas a aquellas personas de su clientela a las que estimó oportuno, como premio a los servicios prestados. 23

La iglesia de Santa María de Medinaceli no había sido la que más había atraído la devoción del primer duque a lo largo de su vida, sino que, según todos los indicios, su predilección se orientó hasta las vísperas de su muerte hacia un monasterio jerónimo que se encontraba ubicado fuera de sus señoríos, el de San Bartolomé de Lupiana.

La Orden de los jerónimos experimentó un notable desarrollo en la Corona de Castilla a fines del Medievo gracias en gran medida al decidido apoyo que encontró en la Monarquía y en varios linajes de alta nobleza. ${ }^{24}$ Los del linaje de La Cerda participaron de esta devoción tan generalizada entre sus pares, aun-

\footnotetext{
21 Ibidem p. 155.

${ }^{22}$ El testamento del primer duque de Medinaceli, Luis de la Cerda, otorgado en Cogolludo, 2-XI1501, y su codicilo, otorgado en la misma villa, 22-XI-1501, en AHN, Osuna, leg. 2023-8.

${ }^{23}$ De esta práctica deja constancia, por ejemplo, el testamento de Hernando de Torres, alcaide de la fortaleza de Medinaceli, otorgado en el año 1583, en el que, refiriéndose a la colegiata, hizo alusión a la «capilla que el duque mi señor tiene dada a los Torres en la dicha santa iglesia». De este testamento se deduce, no obstante, que el duque también controlaba los enterramientos en otras iglesias de la villa, pues esta caballero manifestó que su opción preferida era ser enterrado en la iglesia de San Martín de Medinaceli, «siendo el duque de Medinaceli, mi señor, servido», es decir, si lo autorizaba el duque. Este testamento en AHPS (=Archivo Histórico Provincial de Soria), C. 19.156.

24 J. R. L. HighFIELD, «The Jeronimites in Spain. Their patrons and success, 1373-1516» The Journal of Ecclesiastical History 34 (1983) 513-533. Y M. A. LADERO QUESADA, «Mecenazgo real y nobi-
} 
que no tenemos constancia de que asumiesen directamente la fundación de una determinada comunidad en particular. Se limitaron a favorecer comunidades ya establecidas, como la ya mencionada de San Bartolomé de Lupiana, hacia la que volcó sus atenciones el primer duque de Medinaceli.

Según varios indicios proporcionados por su testamento, mostró a lo largo de su vida fuerte devoción por la Orden jerónima, que, por motivos que desconocemos, se apagó bruscamente semanas antes de que le llegase la muerte. En su testamento, otorgado el 2 de noviembre de 1501, éste, rompiendo con una larga tradición familiar de elegir como lugar de enterramiento el monasterio cisterciense de Santa María de Huerta, ${ }^{25}$ retomada después por su hijo y sucesor, el segundo duque, Juan de la Cerda, ${ }^{26}$ ordenó que se le enterrase en el monasterio de San Bartolomé de Lupiana, en el que también sabemos que había mandado hacer cierto edificio, de características, no obstante, no precisadas en el testamento del duque.

La fuerte vinculación afectiva que le unía con este monasterio quedó manifiesta en la disposición de este mismo testamento para que, hasta que sus hijos llegasen a la edad de 20 años, y tuviesen capacidad para administrar su propia hacienda, determinados bienes muebles de elevado valor que les dejaba en herencia, como eran joyeles, piedras, perlas, zafiros y plata dorada, quedasen en poder del prior de este monasterio. Y, en esta misma línea, también resulta muy revelador el que designase como uno de sus tres testamentarios al general de la Orden de San Jerónimo.

Son muchos, pues, los indicios que demuestran que el primer duque de $\mathrm{Me}$ dinaceli mantuvo una fuerte vinculación con los frailes jerónimos, muy particular en su monasterio de San Bartolomé de Lupiana, el más próximo a sus señoríos sorianos. Pero lo verdaderamente sorprendente de esta relación es que en sus últimas semanas de vida algún acontecimiento que nos ha resultado imposible precisar la trastocó de forma radical, pues apenas veinte días después de haber otorgado su testamento, el 22 de noviembre de 1501, el duque otorgó un codicilo en el que designó nuevos testamentarios, entre los que, por supuesto, ya no figuraba el general de la Orden de San Jerónimo, y dispuso que se le enterrase en la iglesia de Santa María de su villa de Medinaceli, en lugar de en el

liario en monasterios españoles: Los jerónimos (Siglos XV y XVI)» Príncipe de Viana. Homenaje a José María Lacarra, Pamplona, 1986, t. II, pp. 409-39.

25 Beltrán de Bearne, primer conde de Medinaceli, en su testamento otorgado en Badajoz, 3-VIII1381, dispuso que se le enterrase en la iglesia del monasterio de Huerta. También se mandó enterrar allí su esposa Isabel de la Cerda, su hijo, el conde Gastón, y el hijo de éste, el conde Luis de la Cerda, que otorgó testamento en Medinaceli, 6-VIII-1447. Tomamos la información de los testamentos de los distintos miembros de la casa de Medinaceli publicados por $\mathrm{M}^{\circ}$. Luisa PARDo RodríGUEZ, Documentación del Condado de Medinaceli (1368-1454), Soria, 1993.

${ }^{26}$ En su testamento el segundo duque de Medinaceli, Juan de la Cerda, ordenó que se le enterrarse en el monasterio de Santa María de Huerta, al que se había de entregar un dosel de brocado, de los mejores que él, para que se colocase obre su tumba, y otro de terciopelo negro para los días de diario. 
monasterio de San Bartolomé de Lupiana, de modo que todas las cosas que con anterioridad había dispuesto que se hiciesen por cuenta suya en el referido monasterio pasasen a realizarse en la referida iglesia.

Dado el poco tiempo transcurrido entre el otorgamiento del testamento y el del codicillo, tan sólo veinte días, causa notable sorpresa advertir tan radical cambio. Pero por el momento no hemos podido determinar los factores concretos que lo provocaron. En cualquier caso el episodio resulta revelador, pues demuestra que las relaciones de patronazgo de los miembros de la alta nobleza respecto a las Órdenes religiosas no fueron prácticamente nunca desinteresadas, sino que acostumbraron a conllevar la exigencia de contraprestaciones, de modo que la aparición de cualquier factor que las pusiese en cuestión podía fácilmente dar al traste con una larga trayectoria de entendimiento y colaboración.

Los condes de Aguilar, del linaje Arellano, asumieron a una escala bastante más modesta que los duques de Medinaceli la función de promotores de la erección de comunidades monásticas en sus señoríos en el tránsito del Medievo a la Edad Moderna. De entonces sólo les conocemos la fundación del convento de clarisas de Nuestra Señora de los Ángeles del Paraíso de Viavero, en la villa riojana de Entrena, acometida por el segundo conde de Aguilar y su esposa en el año 1503.27

Se trató de una empresa aislada, de escasa envergadura, que sólo encontró continuidad más de un siglo después, en 1617, cuando el séptimo conde de Aguilar acometió la fundación del convento de franciscanos de San Antonio, en la villa de Nalda, erigido en panteón familiar, en sustitución de la capilla de los Santos Mártires, Emeterio y Celedonio, de la catedral de Calahorra, que había sido el lugar preferido por los señores de Cameros del linaje Arellano para sus enterramientos desde los tiempos del primero de ellos, Juan Ramírez de Arellano. ${ }^{28}$

Bastante menos relevante en este terreno fue la actividad de los condes de Monteagudo. Por lo que hemos podido averiguar, no acometieron ninguna fundación en este período, aunque intervinieron directamente en tareas de reconstrucción de los monasterios de San Francisco y de Santa Clara de su villa de Almazán, fundados con bastante anterioridad al momento en que este linaje obtuvo, por merced del rey Enrique III, el señorío jurisdiccional sobre esta villa en 1395.29

\footnotetext{
${ }^{27}$ Sobre esta fundación Vid. Raimundo Aguilar, «El Monasterio de Santa Clara o de Nuestra Señora de los Ángeles del Paraíso de Viavero en Entrena (La Rioja)» Berceo 58 (1961), pp. 67-80, 59 (1961), pp. 177-191, y 60 (1961), pp. 333-348.

28 Vid. Miguel A. Moreno RAmírez DE AREllano, «Claves para la fundación de un convento franciscano extramuros de la villa de Nalda» Berceo 120 (1991) 83-102.

${ }^{29}$ El monasterio de Santa Clara fue fundado en el siglo XIII, y el de San Francisco en el siglo XIV. Vid. J.A. MÁrQuez MuÑoz, «Otros conventos de clarisas en la provincia» Celtiberia 71 (1986) 135-172.
} 
Por lo que respecta al de San Francisco simplemente sabemos que en 1423 se hundió gran parte de su edificio y el señor de Almazán, además de contribuir a la financiación de los gastos que conllevó su reconstrucción, negoció la obtención en Roma de letras apostólicas del Papa Martín V para que se concediese licencia para pedir limosna a fin de recaudar dinero con que poder acometer su reconstrucción..$^{30}$

Por lo que toca al monasterio de Santa Clara, consta que, en los primeros años del siglo XVI, su primitivo edificio quedó destruido por un incendio, ${ }^{31}$ a raíz de lo cual el conde de Monteagudo, Antonio Hurtado de Mendoza, decidió ponerse al frente de la tarea de su inmediata reconstrucción, pero en un emplazamiento diferente del ocupado hasta entonces. La decisión no debió ser bien acogida por las monjas y se produjeron algunos tensos enfrentamientos entre ambas partes. De ellos daremos cuenta más adelante, al analizar la política de intervencionismo de la casa condal de Monteagudo en los asuntos internos de las comunidades de franciscanos y clarisas de Almazán, la capital de su estado señorial. Aquí nos limitaremos a dejar constancia de que, en el transcurso del año 1513, el conde se puso al frente de la empresa de reconstrucción del monasterio, y animó a sus vasallos a que contribuyesen con dinero a la misma. Así lo demuestra el acta de la reunión del concejo de Almazán, de uno de agosto de 1513 , en la que se recoge el compromiso de esta institución de contribuir a la referida obra de reedificación con sus limosnas, que expresamente se hizo constar que se asumía atendiendo al deseo manifestado por su señor el conde.

En conclusión, podemos advertir que, aunque todos los linajes de alta nobleza aspiraron a contar con algún monasterio sometido estrechamente a su patronazgo, y este objetivo resultaba más fácil de alcanzar en los que habían sido directamente fundados por ellos, no todos tuvieron oportunidad o medios para hacerlo, a veces, como ocurrió, por ejemplo, en Almazán, porque ya existían prestigiosas comunidades monásticas, que apenas dejaban lugar para nuevas fundaciones.

PATRONAZGO E INJERENCIAS EN COMUNIDADES MONÁSTICAS UBICADAS EN SUS ÁMBITOS REGIONALES DE INFLUENCIA

Los miembros de la alta nobleza castellana durante el período bajomedieval no se limitaron a tratar de ejercer su influencia sobre comunidades monásticas fundadas y dotadas por ellos, o sus antepasados más próximos. Con frecuencia

\footnotetext{
30 Ibidem p. 142.

${ }^{31}$ A comienzos de la década de 1540 la monja Mencía López de Vargas declaró que al tiempo que se quemó el monasterio de Santa Clara de Almazán las monjas que en él vivían fueron repartidas por otros monasterios, y ella fue una de las que más tardaron en volver a Almazán. Esta declaración en AChV, P.C. Pérez Alonso, F. 847-5.
} 
también trataron de inmiscuirse en los asuntos internos de otras comunidades monásticas ya existentes antes de que se consolidasen sus propios estados señoriales, y ubicadas fuera de los mismos.

En la región soriana no hubo ningún monasterio benedictino importante, pues los que se ubicaban en su flanco septentrional, en concreto los riojanos de Santa María de Valvanera, Santa María de Nájera y San Millán de la Cogolla, se encontraban fuera del radio de acción de los linajes de alta nobleza a los que aquí estamos prestando atención.

Los Arellano, con fuerte implantación señorial en el territorio camerano y riojano, sí podrían haberse interesado por algunos de estos monasterios, bastante próximos a sus dominios, pero no lo hicieron, dejando la iniciativa en manos de los dos linajes que rivalizaron con ellos por la hegemonía en la región, los Velasco y los Manrique. Estos sí mostraron un fuerte interés por intervenir en los asuntos internos de estos monasterios benedictinos, en más de una ocasión recurriendo incluso al ejercicio de la fuerza para imponer al frente de las correspondientes comunidades monásticas personas de su confianza. ${ }^{32}$

En contrapartida los Arellano prefirieron centrar sus intervenciones de forma prácticamente exclusiva en un único monasterio, en el que no tenían que rivalizar con ningún otro linaje noble por afianzar su influencia. Se trata del de Santa María de Herce, de la Orden del Císter, fundado por un antecesor suyo en el señorío de Cameros, aunque de otro linaje, el de los Haro. ${ }^{33}$

Desde que los Arellano se hicieron con el control del señorío de los Cameros, gracias a la merced efectuada por el rey Enrique II a Juan Ramírez de Arellano en premio a los servicios militares prestados, ${ }^{34}$ los de este linaje, de origen navarro, se apresuraron a someter al monasterio de Santa María de Herce, del que se erigieron por la fuerza en encomenderos, a una tutela cada vez más rigurosa, hasta llegar a disponer de sus bienes como si de su propio patrimonio se tratase.

32 Sobre intervenciones de los linajes Velasco y Manrique en los asuntos internos de los monasterios benedictinos riojanos Vid. Máximo DiAGo HERNANDO. «El intervencionismo nobiliario en los monasterios riojanos durante la Baja Edad Media. Encomiendas y usurpaciones» Hispania 182 (1992) 811-61. «La reforma de los monasterios riojanos en tiempo de los Reyes Católicos» Hispania Sacra 90 (1992) 667-97. «El poder de la nobleza en los ámbitos regionales de la Corona de Castilla a fines del Medievo: Las estrategias políticas de los grandes linajes en la Rioja hasta la revuelta comunera» Hispania 223 (2006) 501-546.

${ }^{33}$ Sobre los Haro como señores de Cameros Vid. Máximo Diago Hernando, «Los Haro de Cameros en los siglos XIII y XIV. Análisis del proceso de su afianzamiento político en el ámbito regional» Anuario de Estudios Medievales 24 (1994) 775-806. Sobre la fundación del monasterio de Herce Vid. Máximo Diago HeRnANDo, «Un monasterio cisterciense...».

34 Vid. Máximo Diago Hernando, «Implantación territorial del linaje Arellano en tierras cameroriojanas a fines de la Edad Media»Berceo 120 (1991) 65-82. Y «Un noble entre tres reinos en la España del siglo XIV: Juan Ramírez de Arellano» Príncipe de Viana 230 (2003) 523-56.

Hispania Sacra, LXIII

127, enero-junio 2011, 7-39, ISSN: 0018-215-X 
Lo demuestra, por ejemplo, el hecho de que el propio Juan Ramírez de Arellano llegase a ceder el usufructo del lugar de La Santa, perteneciente al señorío del monasterio, a Doña Urraca Álvarez de Haro, para compensarla por la renuncia de ciertos derechos que alegaba que le pertenecían al señorío de Cameros. ${ }^{35}$

La imposición a los monasterios de encomiendas forzosas por la alta nobleza fue un fenómeno generalizado en la Corona de Castilla en la segunda mitad del siglo XIV. El rey Juan I trató de ponerles fin mediante la aprobación en las Cortes de Soria del año 1380 de una rigurosa legislación que las prohibía, la cual fue ratificada de nuevo en las Cortes de Guadalajara de 1390, ante las fuertes resistencias con las que se había tropezado a la hora de garantizar su cumplimiento. ${ }^{36}$

En aplicación de esta legislación, Juan Ramírez de Arellano, al igual que otros nobles en la región riojana, fue requerido para que dejase al monasterio de Santa María de Herce y a sus lugares de señorío en plena libertad, y renunciase al ejercicio del papel de encomendero. ${ }^{37}$ La documentación conservada no permite determinar en qué medida acató estas órdenes, pero lo que sí sabemos con certeza es que la legislación contra las encomiendas aprobada por las Cortes de Soria en 1380, y ratificada en las Cortes de Guadalajara de 1390, no puso fin a las presiones ejercidas por parte de los señores de Cameros del linaje Arellano sobre Santa María de Herce, pues volvemos a tener noticia de ellas décadas más tarde, en varias ocasiones.

En 1456 la abadesa de este monasterio denunció que los vecinos de la villa de Herce, de señorío monástico, se habían entregado voluntariamente en encomienda a Juan Ramírez de Arellano, tercer señor de Cameros de su linaje. En su papel de encomendero, éste había nombrado un alcalde, y acudía a residir cuando quería a unas casas que se había hecho edificar en la villa. El origen del conflicto estaba en que los vecinos de Herce, o al menos un sector de los mismos, estaban descontentos con el señorío ejercido en la villa por la abadesa, y, para liberarse del mismo, habían recurrido a la estrategia de elegir como encomendero al poderoso señor de Cameros.

Tras varias alternativas los vasallos se reconciliaron con su señora, cuando los jueces árbitros nombrados por ambas partes pronunciaron una sentencia de concordia en el año 1457, que trató de resolver todos los litigios pendientes.38

\footnotetext{
${ }^{35}$ AHN, Diversos, Títulos y Familias, Señorío de Cameros, carpeta 9, nº 66.

36 Vid. J. L. SAntos Díez, La encomienda de monasterios en la Corona de Castilla. Siglos X-XV, Roma-Madrid, 1961.

37 Vid. Máximo Diago HeRnANDO. «El intervencionismo nobiliario...» pp. 833-41.

${ }^{38}$ La sentencia de los jueces árbitros que puso fin al pleito entre el monasterio de Santa María de Herce y los vecinos de la villa de Herce, del año 1457, en AHN, Clero, leg. 2.862, doc. $n^{\circ} .74$ del libro de compulsa de documentos. Para toda la documentación relativa al monasterio de Santa María de Herce Vid. también Pedro Pérez Carazo, Santa María de Herce y su abadengo en la Edad Media, Logroño, 2007.
} 
Cabe presumir que, después de esta reconciliación, el señor de Cameros se viese forzado a dejar de ejercer las funciones de encomendero.

Sus descendientes, de nuevo a principios del siglo XVI, en los turbulentos años que siguieron a la muerte de Isabel la Católica, se volvieron a ver tentados por la idea de someter a su dominio la villa de Herce, chocando en esta ocasión por este motivo frontalmente con una abadesa que, paradójicamente, pertenecía a su mismo linaje, pues era también una Arellano.

Consta que en 1506, el conde de Aguilar, que repetidamente había manifestado con anterioridad su intención de ejercer como encomendero del monasterio de Santa María de Herce, aunque siempre había chocado con la oposición de la Monarquía, que le había negado tal derecho, ${ }^{39}$ decidió aprovechar el vacío de poder que en Castilla había creado la muerte repentina del rey Felipe de Habsburgo, para tratar de alcanzar su propósito mediante el uso de la fuerza bruta.

Acompañado por su primo, el señor de Ausejo, Juan de Arellano, entró al frente de un numeroso grupo de hombres armados en la villa de Herce para ocuparla, y tomó por la fuerza la posada de Alonso de Arellano, a quien al parecer intentó matar. La abadesa, que era hermana de uno de los agresores, el señor de Ausejo, buscó apoyo en la lejana Curia de Roma, donde logró que el Papa Julio II expidiese una bula de excomunión contra el conde de Aguilar, que también recibió una severa reprimenda de los órganos de gobierno central de la Monarquía, muy debilitados en aquellos momentos y con escasa capacidad para asegurar la ejecución de sus órdenes.

Con el regreso a Castilla de Fernando el Católico cabe presumir que las aguas volvieran a su cauce, y que la presión ejercida por los Arellano sobre el monasterio de Santa María de Herce y sus señoríos remitiese. Pero, cuando apenas habían transcurrido unos pocos años desde esta entrada violenta del año 1506, el conde de Aguilar volvió en 1512 a ser denunciado por haber efectuado una nueva entrada en la villa de Herce. Entonces consiguió, gracias a la mediación de su criado Miguel de Vidaurreta, residente en ella, que varios de sus vecinos le jurasen como su encomendero, mientras que los criados y servidores de la abadesa se negaron y no se incorporaron a su «parcialidad», siendo obligados a huir de sus casas y a perder gran parte de sus bienes..$^{40}$

Al margen de estas intervenciones de los condes de Aguilar cuyo principal objetivo fue extender su autoridad a los lugares de señorío del monasterio, y muy en particular a la villa de Herce, es posible que también las hubiese enca-

\footnotetext{
${ }^{39}$ Así se le recordó al conde en una provisión en AGS, RGS, I-1507. En esta provisión se le recriminaba por haber entrado con gran cantidad de gente en la villa de Herce, pese a que ya se le había prohibido con anterioridad que ejerciese la encomienda sobre el monasterio de Santa María de esta villa.

${ }^{40}$ Información sobre este episodio en dos provisiones dirigidas al corregidor de Logroño en AGS, RGS, V-1512.
} 
minadas a interferir en la vida interna de la comunidad monástica, para favorecer determinados modelos de vida en religión en detrimento de otros.

No disponemos de informaciones relativas a la actitud demostrada por los miembros de este linaje hacia la introducción de la reforma observante en las comunidades monásticas de su entorno, y muy en particular en las de la Orden del Císter. Desde un punto de vista general cabe advertir que los miembros de la alta nobleza adoptaron en la Corona de Castilla posturas muy diversas. Mientras unos se movilizaron para asegurar la introducción de la reforma en monasterios cistercienses y, sobre todo, benedictinos, otros no escatimaron en medios para tratar de obstaculizar las labores de los reformadores, cuando no se dio el caso de que un mismo noble en unos momentos apoyó la introducción de la reforma en un monasterio, y en otros se opuso vehementemente a que otro fuese reformado. ${ }^{41}$

En concreto, consta que en el año 1510 acudió al monasterio de Santa María de Herce un reformador de la Orden de San Bernardo de la Observancia, con la intención de visitarlo y reformarlo. Y manifestó entonces que se recelaba de que algunas personas le pondrían impedimentos para llevar a cabo su misión, por lo que solicitó el auxilio del brazo real. ${ }^{42}$

Nada sabemos sobre la identidad de esas personas, pero, teniendo en cuenta los antecedentes de intervencionismo en los asuntos del monasterio de los distintos miembros del linaje Arellano, no es improbable que entre ellas figurarasen el conde de Aguilar u otros parientes suyos.

Si los Arellano centraron sus intervenciones en el monasterio cisterciense de Santa María de Herce, los de La Cerda lo hicieron en el de Santa María de Huerta, perteneciente a esta misma Orden, ubicado en las proximidades de su ducado de Medinaceli, y muy próximo a la frontera de Aragón. La devoción mostrada por los condes y duques de Medinaceli hacia esta casa se tradujo en su elección como lugar de enterramiento por muchos de ellos, desde tiempos del primer conde, Beltrán de Béarn y su esposa Isabel de la Cerda, y en numerosas donaciones a cambio de la exigencia de la celebración por los monjes de misas y otros oficios litúrgicos

Esto no impidió que, en más de una ocasión, criados suyos, contando sin duda con su pleno apoyo, protagonizasen graves acciones de agresión contra el monasterio o su patrimonio. En 1504, en vida de la reina Isabel la Católica, el abad de Huerta, fray Sebastián de Campuzano, denunció que en un día del mes de febrero Pedro de Uceda, alcaide de la fortaleza de Montuenga, una de

${ }^{41}$ Se analizan algunos ejemplos en Máximo Diago Hernando, «La reforma de los monasterios riojanos...». Y «La tutela nobiliaria sobre los monasterios benedictinos castellanos en la Baja Edad Media: Relaciones entre los Velasco y el monasterio de Oña» Hispania Sacra 56 (2004) 69-102.

${ }^{42}$ AGS, RGS, III-1510. Provisión dirigida a los justicias de Calahorra y de otros lugares del entorno para que proporcionasen el auxilio del brazo real al referido reformador. 
las principales del ducado de Medinaceli, había irrumpido al frente de un grupo de personas armadas en los términos del monasterio, procediendo a continuación a descepar una viña perteneciente a éste, a apresar a unos criados suyos, y a llevarse consigo seis pares de bueyes y mulas, y otros ganados. ${ }^{43}$

No fue ésta la única vez en que desde esta fortaleza se perpetraron agresiones contra el monasterio, pues en 1520 se denunció que, habiendo ido un reformador de la Orden del Císter a visitar Huerta, al alcaide de la fortaleza de Montuenga le impidió por la fuerza que realizase la visita, para lo cual llegó a encastillar el propio edificio monástico. ${ }^{44}$

El carácter aislado de esta noticia nos impide determinar si la iniciativa de oponerse a la introducción de la reforma observante en el monasterio había sido exclusiva del referido alcalde, o éste había actuado siguiendo instrucciones de su señor el duque, Juan de la Cerda. Más probable nos parece lo segundo, ya que en asunto de tal envergadura resultaba muy arriesgado para un criado tomar decisiones sin el consentimiento de su señor. Sería deseable que prospecciones más sistemáticas en la documentación permitieran conocer con más de detalle la actitud de los duques de Medinaceli hacia la reforma observante en los monasterios sobre los que aspiraban a ejercer influencia, como era el caso muy en particular de Santa María de Huerta.

Al margen de estas noticias, algunas otras corroboran que la relación del linaje de La Cerda con Santa María de Huerta estuvo marcada por el signo de la duplicidad y la contradicción, en la medida en que lo que los condes y duques le daban con una mano, por la vía de mandas testamentarias, ${ }^{45}$ se lo quitaban con la otra, a través de agresiones, que solían conllevar ocupaciones de términos. Interesa recordar que hacia 1499 los Reyes Católicos comisionaron al bachiller Juan de Molina para que restituyese al monasterio de Huerta ciertos términos que el duque de Medinaceli, así como la villa ducal y los lugares de su Tierra, le tenían tomados. ${ }^{46}$

Los duques de Medinaceli eran los nobles más poderosos con los que tenía que lidiar el monasterio de Huerta en la Corona de Castilla. Pero su proximidad al reino de Aragón propició que también estuviese expuesto a los ataques de los nobles aragoneses. Hay noticia de algunos que alcanzaron notable gravedad,

\footnotetext{
${ }^{43}$ AGS, RGS, III-1504. Comisión al bachiller Gonzalo de Grijera.

${ }^{44}$ AGS, RGS, VI-1520.

${ }^{45}$ Por ejemplo el segundo duque, Juan de la Cerda, dispuso que 1.500 del total de 5.000 misas que encargó en su testamento por su alma se celebrasen en el referido monasterio, pagando a los monjes la limosna correspondiente. Por su parte su antepasado, el conde Luis de la Cerda, en su testamento del año 1447 declaró que había encargado realizar a su costa un retablo para la iglesia de este monasterio, al que además hizo una manda de 10.000 mrs. para financiar la reparación de la referida iglesia. Vid. María Luisa PARDO, op. cit. doc. no 200 (pp. 460-7).

${ }^{46}$ Noticia en AGS, RGS, III-1504. Comisión al bachiller Gonzalo de Grijera.
} 
como el perpetrado en 1524 por el señor de Ariza, Francisco de Palafox, quien irrumpió al frente de un numeroso grupo de personas armadas en tierras del reino de Castilla, tomando presos a dos monjes y a varios criados y familiares del monasterio y los llevaron a una fortaleza del reino de Aragón. ${ }^{47}$

Mientras que las injerencias de los duques de Medinaceli y de los condes de Aguilar en comunidades monásticas se centraron en monasterios cistercienses ubicados en las proximidades de sus señoríos, pero fuera del territorio sobre el que ejercían jurisdicción, los condes de Monteagudo se limitaron a intervenir en conventos de los lugares de los que eran señores jurisdiccionales. Es el caso de los de San Francisco y Santa Clara de su villa de Almazán, la capital de su estado señorial. ${ }^{48}$

El sentido de sus intervenciones en los dos no resulta fácil de interpretar a partir de las escasas y fragmentarias informaciones de que disponemos, que además en ocasiones son parciales. Parece fuera de duda, no obstante, que, a principios del siglo XVI, el segundo conde de Monteagudo, que tenía precisamente dos hermanas monjas en Santa Clara, una de las cuales llegó a ser abadesa, sometió a este monasterio y al de San Francisco a una rigurosa tutela, hasta el punto de llegar a tomar graves medidas de represalia contra ambos, cuando trataron de ofrecer resistencia a alguna de sus decisiones.

En este sentido interpretamos el hecho de que el referido conde llegase a prohibir a todos sus vasallos, vecinos de Almazán, que concediesen limosnas a los dos monasterios. Sabemos de dicha prohibición porque nos consta que en agosto de 1513 cursó orden al procurador de la villa de Almazán para que, en adelante, se volviese a acudir a dichos monasterios con los maravedís de limosna que se había acostumbrado entregarles, pese a que en los últimos años no se había hecho. El único argumento para justificar la decisión fue que sus señorías, es decir, el conde y su esposa, «eran servidos que así se les debe de pagar». ${ }^{49}$

No podemos precisar las razones de la prohibición, suspendida a partir del verano de 1513, pero sospechamos que tuvieron su origen en la oposición de las comunidades monásticas a la reedificación del monasterio de Santa Clara en un emplazamiento diferente del que hasta entonces había ocupado, extramuros de la villa. Y a esta misma motivación creemos que obedecieron los violentos sucesos que tuvieron lugar en Almazán en febrero de 1513, cuando, según denuncia presentada en la Corte por los representantes de las propias clarisas, el

\footnotetext{
47 AGS, RGS, II-1524 (2º).

48 Sobre Almazán como capital del estado señorial de los condes de Monteagudo Vid. Máximo Diago HernANDo, «Almazán en época de los Reyes Católicos. Estructura social de una pequeña capital de estado señorial» En la España Medieval 16 (1993) 239-64.

${ }^{49}$ Archivo Municipal de Almazán, libros de actas, leg. 1-4. Reunión de 5-VIII-1513.
} 
conde Don Antonio Hurtado de Mendoza y su criado Álvaro de Luna, individuo de origen judeoconverso que desempeñó en varias ocasiones los oficios de alcalde y regidor de Almazán, acompañados por gran número de personas, irrumpieron en el monasterio de Santa Clara, rompieron una pared y se llevaron por la fuerza a la abadesa y a las monjas a un mesón de la villa «muy publico e disonesto en que hay mujeres publicas», y luego las trasladaron a un hospital. Y, en otro día de ese mismo mes de febrero, el mismo conde y su esposa, Doña María de Mendoza, al frente de unos 300 hombres, tomaron por la fuerza todo el trigo, cebada y provisiones que había en el monasterio. ${ }^{50}$

Probamente estos episodios, denunciados en la Corte por los representantes de las clarisas adnamantinas, estuviesen directamente relacionados con el proyecto del conde de Monteagudo de reedificar el monasterio lejos de su emplazamiento original, al que se opondrían las monjas, por razones desconocidas. También cabe la posibilidad de que no sólo estuviese en juego un cambio de emplazamiento, sino también la introducción de otras novedades en el régimen de vida conventual, como las propiciadas por los reformadores observantes, a las que se opusiesen las monjas. No hemos encontrado ninguna noticia concluyente en la documentación que permita corroborar esta hipótesis. En cualquier caso, al margen de cuáles fuesen los motivos del conflicto, lo que aquí interesa resaltar es el hecho de que el conde y su esposa no vacilasen en recurrir al uso de la fuerza para imponer sus criterios a una comunidad monástica en la que, en principio, no tenían ningún derecho a intervenir.

RELACIONES CON EL CLERO SECULAR E INTERVENCIONES EN LAS DISPUTAS POR EL ACCESO A LAS SILLAS EPISCOPALES

En los obispados de la Corona de Castilla durante el período bajomedieval se plantearon en bastantes casos cismas, es decir disputas entre dos candidatos por ocupar una determinada silla episcopal. En ellos se vieron habitualmente implicados miembros de la alta nobleza con fuerte implantación señorial en el obispado en disputa, que tomaron abiertamente partido por uno de los candidatos, con el que podía darse el caso de que estuviesen emparentados.

En el obispado de Osma se planteó un grave conflicto de este tipo, en que se involucró de forma muy directa una rama del linaje de los Mendoza, la de los señores de Gormaz, a comienzos del reinado de los Reyes Católicos. Tras la muerte del obispo Don Pedro de Montoya, que había mantenido estrecha relación con este linaje, hasta el punto de que, como hemos visto, llegó a ca-

50 AGS, RGS, V-1513. Comisión al licenciado Francisco González de la Torre para que vaya a tomar información sobre las denuncias presentadas por el monasterio de Santa Clara de Almazán.

Hispania Sacra, LXIII

127, enero-junio 2011, 7-39, ISSN: 0018-215-X 
sar a su hija, María de Montoya, con un hijo del señor de Almazán, Diego de Mendoza, dos candidatos se disputaron su sucesión en la silla episcopal oxomense.

Uno era Luis Hurtado de Mendoza, hermano del conde de Castro, señor de Gormaz. Fue elegido obispo por votación entre los miembros del cabildo de la catedral de El Burgo de Osma. El otro fue Diego de Santillán, sevillano y hermano del comendador mayor de Alcántara, Diego de Santillán, quien recibió su nombramiento directamente del Papa Sixto IV.

Dado el desorden político reinante en la Corona de Castilla, inmersa en plena guerra por la sucesión al trono entre los partidarios de Isabel la Católica y los de la princesa Juana, hija del difunto rey Enrique IV, ambos candidatos recurrieron a las armas para hacer prevalecer su derecho. Luis Hurtado de Mendoza se aprestó a apoderarse de la villa episcopal de El Burgo de Osma, donde tenía su sede el cabildo catedral.

El hermano de su rival, el comendador mayor de Alcántara, pues el interesado residía en Roma, se hizo fuerte en la villa de Ucero, también dependiente del señorío episcopal oxomense. Desde estas bases, las dos partes se lanzaron a combatirse mutuamente con gran encarnizamiento, provocando de este modo numerosos robos y otros actos destructivos. Sus principales víctimas fueron los campesinos del entorno, como testimonian, por ejemplo, las denuncias de los vecinos de la villa de Ucero. Éstos estimaron que las pérdidas sufridas como consecuencia de los ataques lanzados contra ellos por las gentes de Luis Hurtado de Mendoza ascendieron a 550.000 mrs. ${ }^{51}$

El enfrentamiento armado duró varios meses. Todavía en marzo de 1477 los Reyes Católicos tuvieron que requerir a las justicias de las ciudades de Soria y de Aranda de Duero para que prestasen ayuda militar a los partidarios de Francisco de Santillán, candidato al que estos monarcas apoyaban, para que pudiesen rescatar la villa de El Burgo de Osma y la fortaleza de la ciudad de Osma de manos de Luis Hurtado de Mendoza y sus partidarios. ${ }^{52}$

La consolidación en el trono de Isabel y Fernando facilitó que el candidato Francisco de Santillán se impusiese frente a su adversario, pese a que éste era un hombre de la tierra y el otro un forastero, de origen sevillano, y además absentista, pues tenía fijada su residencia en Roma. Luis Hurtado de Mendoza tuvo que renunciar a sus pretensiones de convertirse en obispo de Osma.

\footnotetext{
51 AGS, RGS, III-1480, fol. 189. Se informa que «Don Luys Furtado de Mendoza se metia en los lugares del dicho obispado e quando tovo la villa del Burgo, desde la qual se avian fecho grandes robos e dannos a la dicha villa de Usero e su Tierra, la qual dicha villa dis que tenia el dicho comendador mayor por el dicho obispo don Françisco de Santillan, desde donde asy mismo fasía guerra al dicho Luys Furtado».

${ }^{52}$ AGS, RGS, III-1477, fol. 460.
} 
No cabe duda de que el que estuviese en condiciones de defenderlas con tanto tesón durante tan prolongado período de tiempo tuvo mucho que ver con su condición de miembro de un linaje de alta nobleza con fuerte implantación en tierras sorianas, tanto del obispado de Osma, al que pertenecían Gormaz y Monteagudo, como del de Sigüienza, del que formaban parte Almazán y Morón, lugares todos ellos sobre los que ejercían el señorío jurisdiccional miembros del linaje Mendoza, todos descendientes de Juan Hurtado de Mendoza, mayordomo de Enrique III.

Otro episodio de disputa por el control de una silla episcopal, bastante menos cruento que el anterior, tuvo lugar en otro momento de grave inestabilidad política para el conjunto de la Corona de Castilla, el que siguió a la muerte de Fernando el Católico en enero de 1516.

La silla objeto de disputa fue la de Sigüenza, y el origen del conflicto hay que retrotraerlo a un suceso que tuvo lugar en Italia en 1512, fecha en que era obispo de Sigüenza un clérigo de origen extremeño que residía en la Curia, Bernardino López de Carvajal, cardenal de Santa Cruz

Por haber presidido éste ese año en la ciudad italiana de Pisa un conciliábulo que apoyó la causa del rey Luis XII de Francia contra el Papa Julio II, fue privado por este último de su sede de Sigüenza. Se nombró en su lugar para ocuparla a Fadrique de Portugal, hasta entonces obispo de Calahorra. ${ }^{53}$

Muerto el Papa Julio II, su sucesor León X decidió reponer a Bernardino López de Carvajal en la dignidad cardenalicia y en todas las demás que había disfrutado con anterioridad a 1512, incluida la silla episcopal de Sigüenza. Fadrique de Portugal no acató, sin embargo, esta decisión papal, y en su oposición a ser privado de su nueva sede contó con el apoyo de Fernando el Católico, primero, y de Carlos I, después. A raíz de ello se planteó entre estos dos prelados una enconada disputa, en el transcurso de la cual el cardenal Carvajal contó con el apoyo de buena parte del clero del obispado, que no bastó, sin embargo, para evitar que su rival, Fadrique de Portugal, saliese finalmente triunfante, gracias al decidido apoyo que le prestó la Monarquía, de modo que a la postre el cisma se resolvió con la renuncia al obispado segontino por el cardenal de Santa Cruz en el año $1519.5^{54}$

Fadrique de Portugal era cuñado del duque de Medinaceli, Juan de la Cerda, como hermano de su primera esposa, Mencía Manuel, que murió, no obstante, varios años antes de que se plantease la disputa por el control del obispado de Sigüenza, cuando el duque estaba ya casado en segundas nupcias con María de Silva. En cualquier caso esta relación de parentesco, un tanto lejana, no nos consta

53 Vid. Toribio Mingueda y ARnedo, Historia de la diócesis de Sigüenza y de sus obispos, Madrid, 1912, vol. II, p. 209.

${ }^{54}$ Ibidem p. 212.

Hispania Sacra, LXIII

127, enero-junio 2011, 7-39, ISSN: 0018-215-X 
que influyese en el comportamiento del duque durante el cisma, pues no hay noticia de que participase activamente en el conflicto, prestando apoyo a su cuñado, pese a que las tierras del ducado formaban parte del obispado de Sigüenza.

Sí consta que se involucraron a fondo en la disputa el conde de Monteagudo, Don Antonio de Mendoza, y su esposa, Doña María de Mendoza, aunque lo hicieron tomando partido por el otro pretendiente, el cardenal de Santa Cruz. Doña María de Mendoza fue una mujer inquieta, con una intensa participación en la vida política del estado señorial de su marido, que nos revela un carácter combativo, en muchos aspectos parecido al de su hermana, la célebre María Pacheco, viuda del regidor toledano Juan Padilla, que encabezó durante varios meses la enconada resistencia al cerco de las tropas realistas, tras la ejecución de su marido en Villalar. Y sus actuaciones durante la disputa por el control del obispado de Sigüenza corroboran esta impresión.

En efecto, los clérigos del arciprestazgo de Almazán, como al parecer la mayoría de los del obispado, al conocerse la decisión de restablecer a Bernardino López de Carvajal en la sede de Sigüenza, se apresuraron a reconocerle como su prelado, probablemente porque entendían que desde la lejana Roma sería incapaz de controlarles con el rigor que podía hacerlo Fadrique de Portugal, al ser éste un obispo residente. Acto seguido declinaron continuar acatando la autoridad de éste, pasando a ofrecer resistencia activa a cumplir sus mandamientos.

En la Corte, donde se apoyaba la causa de Fadrique de Portugal, se decidió enviar a Almazán y a otros lugares del obispado de Sigüenza a un juez pesquisidor, el licenciado Calderón, para que tomase información sobre los actos de desacato a su prelado cometidos por los clérigos del obispado, y castigase a los culpables.

Este juez se encontraba en Almazán en enero de 1517, acompañado por un criado del obispo Don Fadrique. Cuando quisieron ambos asistir a misa en el convento de San Francisco, el conde de Monteagudo ordenó al fraile que la había de celebrar que no lo hiciese. Por temor al conde, su señor, el fraile se metió en el claustro, y allí celebró la misa sólo para el conde, después de que éste hubiese ordenado que se cerrasen las puertas al licenciado Calderón y a su acompañante..$^{55}$

El episodio, denunciado por el juez pesquisidor ante el Consejo Real, para demostrar que el señor de Almazán se había empeñado en torpedear su misión por motivos de animadversión personal hacia él, demuestra hasta dónde llegaba la capacidad de algunos miembros de la alta nobleza para ejercer presión sobre el clero de sus lugares de señorío, a los que podían llegar incluso a dictarles dónde y cómo habían de celebrar los oficios litúrgicos.

\footnotetext{
55 AGS, RGS, I-1517.
} 
Volveremos a insistir más adelante sobre esta cuestión. Ahora, seguiremos prestando atención a las actuaciones de los condes de Monteagudo en el año 1517, que demuestran el elevado grado de implicación de los mismos en la disputa por el control de la silla episcopal seguntina, en la que tomaron decididamente partido por uno de los pretendientes, el que no contaba con el apoyo de la Monarquía. Se ha de destacar el hecho de que, habiendo el licenciado Calderón llevado preso al abad del cabildo de clérigos de Almazán a la villa de Monteagudo, para obligarle después a comparecer en Sigüenza ante Fadrique de Portugal y responder de las acusaciones que se habían presentado contra él, la condesa de Monteagudo aprovechó una ausencia del pesquisidor para entrar por la fuerza en la posada donde se encontraba el abad preso y liberarlo. ${ }^{56}$

Demostró ésta así que, en su afán por prestar apoyo a los clérigos de Almazán y su Tierra que no reconocían a Fadrique de Portugal como obispo de Sigüenza, era capaz de desafiar a la propia Monarquía, que había enviado al juez pesquisidor. Además de en Almazán hubo clérigos rebeldes en otras jurisdicciones del obispado, como, por ejemplo, Berlanga, donde el licenciado Calderón fue requerido para que proporcionase el auxilio del brazo secular para prender a algunos de ellos.$^{57}$ No consta, sin embargo, que en este caso los clérigos contasen con el apoyo del señor de la villa, miembro del poderoso linaje de los Velasco, Condestables de Castilla.

Fueron los condes de Monteagudo los únicos representantes de la alta nobleza en el obispado de Sigüenza que se significaron por su firme apoyo a los clérigos rebeldes, hasta el punto de recurrir incluso al uso de la fuerza en defensa de su causa. Cuáles fueron las razones que les llevaron a actuar así resultan difíciles de determinar con precisión, pero, en honor a la verdad, cabe recordar que las relaciones entre los condes y los clérigos seculares de sus señoríos, en particular los de la villa de Almazán, conocieron también momentos de fuerte tensión. Lo comprobaremos en el siguiente epígrafe.

INTERVENCIONES EN LA REGULACIÓN DE LAS PRÁCTICAS RELIGIOSAS Y DE LAS CELEBRACIONES LITÚRGICAS

Los miembros de la nobleza se inmiscuyeron con inusual frecuencia en la época que estamos analizando en la regulación de la celebración de actos litúrgicos, demostrando de este modo hasta qué punto consideraban la regulación

\footnotetext{
56 AGS, RGS, II-1517.

${ }^{57}$ Información al respecto en varias provisiones en AGS, RGS, III-1517. En una de dichas provisiones se hace constar que los clérigos de Berlanga, alegando que había sede vacante, habían nombrado como vicario a un clérigo llamado Hernán Sánchez.

Hispania Sacra, LXIII

127, enero-junio 2011, 7-39, ISSN: 0018-215-X
} 
de la práctica religiosa como un elemento fundamental de la acción política. Se trataba por regla general de actos litúrgicos de carácter solemne, que, además de un indiscutible componente religioso, tenían también un evidente carácter de acontecimiento social, que se consideraba preciso regular desde las instancias de ejercicio del poder.

Los miembros de la alta nobleza, en su función de gobernantes, como titulares de la jurisdicción civil y criminal en sus señoríos, se preocuparon, en efecto, por intervenir en la regulación de la celebración de misas, procesiones y otros actos litúrgicos. Y este interés no cabe duda de que en importante medida era consecuencia de que estas ceremonias tuvieron en la época un importante componente político.

Esta peculiaridad de las celebraciones litúrgicas en las sociedades medievales y del Antiguo Régimen ya ha sido puesta de relieve en diversos estudios, de entre los que cabe destacar los centrados en el análisis de la festividad del Corpus Christi, sin duda la de más manifiesto contenido político de cuantas se celebraron con carácter generalizado en los reinos hispánicos, y en el conjunto de la Europa occidental, en esta época. Y, de entre los numerosos estudios dedicados al estudio de la fiesta, y, muy en particular, de las procesiones que se organizaban con ocasión de la misma, interesa aquí destacar los que han prestado atención en concreto a la cuestión del papel desempeñado por los linajes de alta nobleza como promotores y reguladores de esta celebración, de contenido en principio eminentemente litúrgico, en sus lugares de señorío. Hay que destacar la monografía de Alejandro López Álvarez sobre el derecho de patronato de la casa ducal de Béjar en la procesión del Corpus de esta villa salmantina, capital de su estado señorial. ${ }^{58}$

En el rastreo de la documentación llevado a cabo no hemos encontrado noticias particularmente significativas sobre la participación de los linajes de la alta nobleza que están centrando nuestra atención en las celebraciones del día del Corpus Christi en sus villas de señorío. Habrá que seguir indagando por si se pudiese obtener información relevante en otros fondos documentales.

Sí hemos podido comprobar que la intervención de estos linajes en la regulación de celebraciones litúrgicas, tanto ordinarias como extraordinarias, fue muy habitual, y en ocasiones dio lugar incluso a que entrasen en abierto conflicto por ello con los propios miembros del estamento clerical. Muy en concreto la mayor parte de la información que hemos conseguido recopilar se refiere a las intervenciones de los condes de Monteagudo, disponiendo cómo habían de tener lugar este tipo de celebraciones en Almazán, la capital de su estado señorial, donde se ubicaba su suntuoso palacio, todavía hoy en pie.

58 Alejandro LóPez Álvarez, Ideología, control social y conflicto en el Antiguo Régimen: El derecho de patronato de la Casa Ducal sobre la procesión del Corpus Christi de Béjar, Béjar, 1996. 
Los libros de actas del concejo de Almazán de los primeros años del siglo XVI dejan constancia de las frecuentes órdenes transmitidas por el segundo conde de Monteagudo, Don Antonio Hurtado de Mendoza, a los oficiales de esta institución para que contribuyesen a la organización de determinadas celebraciones religiosas o participasen en ellas. Es el caso de la escenificación de la Estoria el día de Domingo de Ramos, o de los actos que se celebraban el día de Pascua de Resurrección, que, con toda probabilidad, incluían algún tipo de escenificación, pues se sabe que el concejo de Almazán tuvo que contribuir a los mismos con la compra de ciertos tejidos «por mandado de su señoría». 59

Los condes también se preocuparon por que las procesiones pudiesen celebrarse con la decencia requerida. En los libros de actas del concejo de Almazán se informa sobre la orden dada por su señoría para que se limpiasen unos muladares que había junto a la barbacana, en un lugar por donde había de pasar en fecha próxima una procesión que tenía que acababa en la iglesia de San Pedro. ${ }^{60}$

Además de su intervención en estos asuntos que no afectaban al contenido propiamente litúrgico de la celebración, también se inmiscuyeron en regular la forma en que habían de celebrarse las procesiones, entrando de este modo de lleno en un terreno que en la actualidad se considera de exclusiva incumbencia eclesiástica.

Las actuaciones del conde de Monteagudo, denunciadas en 1517 por el licenciado Calderón, pueden considerarse un primer testimonio de esta forma de proceder. Pero mucho más ilustrativas resultan desde este punto de vista las noticias que nos proporciona una ejecutoria de la Chancillería de Valladolid, de julio de 1557, que puso fin a un enconado conflicto que enfrentó desde el año 1555 al conde de Monteagudo con el cabildo antiguo de curas y beneficiados de Almazán. ${ }^{61}$

Según se informa en esta ejecutoria, en agosto de 1555 compareció en Valladolid ante el Consejo Real un procurador en nombre del cabildo para presentar una denuncia contra el conde de Monteagudo, Francisco Hurtado de Mendoza. Le acusó de haber interferido recientemente en varias ocasiones de forma violenta en la celebración de varias procesiones solemnes que se tenía por costumbre realizar en Almazán.

El primer suceso grave tuvo lugar con ocasión de la celebración de la fiesta de San Sebastián, el 20 de enero de 1555. Este día era costumbre en Almazán realizar una procesión solemne desde la iglesia de San Pedro hasta la de Nuestra Señora del Campanario, donde, al entrar, recitaban una salutación a Nuestra Señora, y se celebraba después una misa mayor solemne en la capilla mayor. El

59 Referencias al respecto en la relación de gastos del concejo de Almazán de 31-VIII-1508, en Archivo Municipal de Almazán, leg. 27.

${ }^{60}$ Archivo Municipal de Almazán, libros de actas, sesión de 28-XI-1514.

${ }^{61}$ AChV, RE, 892-23 (VII-1557). 
20 de enero de 1555, después de haber recorrido, como todos los años, el trayecto que separaba la iglesia de San Pedro de la de Nuestra Señora del Campanario, cuando estaban iniciando el acto de la salutación a la Virgen, se presentó el conde en persona «con mucho enojo», e impidió a los clérigos del cabildo que continuasen, llamándoles «desvergonzados» y profiriendo otras palabras injuriosas contra ellos.

Los clérigos, atemorizados, prescindieron de celebrar la misa solemne en la capilla mayor, como era costumbre, y lo hicieron en otra capilla. Ni siquiera así lograron ponerse a salvo de la ira del conde, pues mientras estaban oficiando la misa, acudió éste a la capilla, acompañado de gran número de personas, y «con gran escándalo y alboroto» impidió que siguiese adelante el oficio litúrgico, profiriendo de nuevo contra los clérigos «palabras feas e injuriosas».

Se reprodujeron los altercados con ocasión de la celebración de la fiesta de San Pedro y San Pablo, el 29 de junio de 1555. Ese día el cabildo acostumbraba a realizar una procesión desde la iglesia de Nuestra Señora de Campanario a la de San Pedro. Pero, cuando los clérigos se encontraban todavía en la primera iglesia, acudió el conde e hizo desnudar por la fuerza al diácono y al subdiácono, revestidos para la misa, profirió palabras injuriosas contra ellos, y les impidió realizar la procesión. No se trató de una simple intervención puntual, sino que, siempre según el cabildo, la intención del conde era hacerse con el pleno control de la organización de las procesiones, desplazando al cabildo. Para ello, contando con la colaboración de sus criados, llegó a establecer un nuevo cabildo, e introdujo importantes novedades en la propia forma de desarrollarse las procesiones, disponiendo, por ejemplo, que fuesen en ellas hombres legos entre los clérigos.

Este afán del conde por hacerse con el control de la organización de las procesiones en Almazán, desplazando al cabildo antiguo de clérigos, volvió a ponerse de manifiesto el día de la fiesta de la Visitación de Santa Isabel, que se celebraba el primer domingo después de San Juan Bautista. Era ésta una fiesta con notable arraigo en aquella época en la región soriana, pues está constatada no sólo en Almazán sino también en la cercana ciudad de Soria, ${ }^{62}$ y en la villa de San Pedro Manrique, ${ }^{63}$ lugares todos en que ocupaba un lugar central en el calendario festivo, y se traducía en singulares celebraciones, no sólo de carácter religioso sino también lúdico, con un fuerte protagonismo popular.

\footnotetext{
${ }^{62}$ Sobre la importancia y singularidad de esta fiesta en Soria, donde también se la llegó a conocer como la fiesta de la Boda de Santa María Vid. Máximo Diago Hernando, «La celebración de la fiesta en la ciudad de Soria a fines de la Edad Media y comienzos de la Edad Moderna (Siglos XV-XVII)» Revista de Soria 42 (2003) 63-78. Y «Las cuadrillas del Común de pecheros, una institución singular en la historia de la ciudad de Soria entre los siglos XIV y XXI» Revista de Soria 60 (2008) 31-46.

63 Carlos Álvarez García, «Sobre el origen de las fiestas de Vinuesa y de San Pedro Manrique» Revista de Soria 10 (1995) 7-26.
} 
En Almazán, entre las ceremonias de ese día, figuraba una solemne procesión hasta la ermita de Nuestra Señora de Prado, tras la cual, en un prado junto a la ermita, se procedía a una distribución de raciones de comida, fundamentalmente carne de toro, a todos los asistentes, incluidos los miembros de la casa condal, que ese día eran obsequiados por sus vasallos. ${ }^{64}$

Por ello a este acto se le denominaba en la documentación de la época caridad. ${ }^{65}$ Pues bien, en el año 1555, según pudo averiguar un juez pesquisidor, el normal desarrollo de la procesión se vio gravemente alterado por las desavenencias surgidas entre el conde y los clérigos del cabildo. En el informe del juez se recogió que ese día iban en procesión cuatro clérigos revestidos, con la imagen de Nuestra Señora portada en andas «con toda veneración», cuando se presentó ante ellos el conde de Monteagudo, «que venía en procesión con los cofrades del Santísimo Sacramento», y procedió a dar una serie de instrucciones que trastocaron drásticamente el orden en que iban colocados los participantes en la procesión, asignando un lugar preferente a los cofrades del Santísimo Sacramento, en detrimento de los clérigos del cabildo, y colocando a gran número de laicos entre estos últimos y los cofrades.

A la cuestión del orden de precedencia en las procesiones se le asignó una gran importancia en la época que estamos considerando, cuando generó innumerables y enconados conflictos, que con frecuencia terminaron en los altos tribunales de la Monarquía. Las actuaciones del conde en el transcurso de la procesión a Nuestra Señora de Prado fueron consideradas, por tanto, de extrema gravedad por el cabildo de clérigos de Almazán, que por ello se apresuró a llevar su denuncia hasta la propia Corte.

Nuestras fuentes de información son fragmentarias y parciales, por lo que resulta difícil llegar a precisar las motivaciones de las partes implicadas. Hay razones para sospechar que el origen del conflicto pudo estar en el empeño demostrado por el conde por favorecer a la cofradía del Santísimo Sacramento. Pero, dado que lo desconocemos prácticamente todo respecto a la misma, no podemos explicar en qué medida tal propósito podía chocar con los intereses del cabildo de clérigos de Almazán.

De lo que no hay duda es de que las actuaciones del conde revelan ante todo un fuerte interés por su parte en hacer prevalecer su autoridad sobre todos sus

\footnotetext{
${ }^{64}$ Nos basamos en información aportada por los libros de actas del concejo de Almazán, de los años 1513 y 1514.

${ }^{65}$ En Soria también tenía lugar un acto de similares características, llamado caridad, en el entorno del priorato benedictino de Nuestra Señora de Mercado o la Blanca, después de una solemne procesión con las imágenes de los santos patronos de las cuadrillas que acababa en dicha iglesia. A diferencia de Almazán y San Pedro Manrique, donde estas celebraciones ya no tienen lugar en la actualidad, en Soria continúan perviviendo, en el mismo día, el primer domingo después de San Juan, llamado de Calderas.
} 
vasallos, tanto clérigos como laicos, hasta el extremo de llegar a interferir en la celebración de actos litúrgicos, y de introducir la violencia en los recintos sacros, para doblegar a los clérigos que se resistían a obedecer sus órdenes.

Un buen ejemplo de hasta dónde podía llegar en este terreno nos lo proporciona lo ocurrido durante la vigilia de la fiesta de San Juan Bautista del año 1555. Según denunciaron los clérigos del cabildo antiguo, envió ese día el conde a la iglesia colocada bajo la advocación de este santo, cuando se estaba celebrando en su interior la vigilia, a su gobernador, Juan de Mendoza. Se subió éste a la tribuna y asió por la mano al prior de la iglesia, que estaba celebrando el oficio divino, y le amenazó diciéndole que le echaría de la iglesia y le llevaría preso a una torre, «porque no hacía lo que el conde quería».

Las interferencias del conde de Monteagudo en actos litúrgicos del cabildo de clérigos de Almazán llegaron a su culminación, no obstante, el día de la fiesta de Santiago, una de las principales en el calendario de la época en toda la Corona de Castilla. De nuevo entonces les impidió por la fuerza que oficiasen la misa, según era costumbre ese día, en la iglesia de Santiago y que los fieles laicos les acompañasen cuando se marcharon a otra iglesia para celebrarla allí, poniendo alguaciles en la puerta de la de Santiago para que no saliesen los fieles congregados en ella.

Sería preciso profundizar en el rastreo de la documentación de estos años centrales del siglo XVI para entender mejor, en todas sus implicaciones, este enconado conflicto del año 1555. Por un lado debemos tener en cuenta que el protagonista de los sucesos, el cuarto conde de Monteagudo, Francisco Hurtado de Mendoza, estuvo muy relacionado con el mundo espiritual de Francisco de Borja, y esta circunstancia puede contribuir a explicar el sentido de algunas de sus actuaciones. ${ }^{66}$ Por otro lado, también nos ha llamado la atención el hecho de que, para descalificar al abad del cabildo, el bachiller Jerónimo Hernández, se llegó a decir de él que era hijo de un reconciliado por el Santo Oficio de la Inquisición. Por ello se nos plantea la duda de si el conde y sus secuaces pudieron actuar movidos por cierto sentimiento anticonverso. Son cuestiones para las que no disponemos de momento de respuesta.

En cualquier caso hemos querido detenernos en dar cuenta de estos sucesos, pese a los numerosos interrogantes que plantean, con el único objetivo de poner de manifiesto hasta qué punto los miembros de la alta nobleza llegaron en su afán por incorporar a sus múltiples atribuciones como gobernantes las relacionadas con la regulación de la práctica religiosa, sobre todo en sus manifestaciones litúrgicas.

${ }^{66}$ Breve semblanza sobre el cuarto conde de Monteagudo, y primer marqués de Almazán, en José Martínez Millán y Carlos J. De CARlos Morales (Dirs.), Felipe II (1527-1598). La configuración de la Monarquía Hispana, Junta de Castilla y León, Valladolid, 1998, pp. 401-3. 